\title{
Current Awareness of Health Professionals on the Safety of Herbal Medicine and Associated Factors in the South West of Ethiopia
}

\author{
Gemmechu Hasen $\mathbb{1}^{1,2}$ \\ Rebuma Hashim ' \\ 'Jimma University, Institute of Health, \\ School of Pharmacy, Jimma, Oromia, \\ Ethiopia; ${ }^{2}$ Jimma University Laboratory \\ Drug Quality (JuLaDQ), Jimma, Oromia, \\ Ethiopia
}

Background: Recently, the World Health Organization has strongly evidenced the importance of herbal medicine safety monitoring within the existing pharmacovigilance system through active involvement of health professionals. However, there is a widespread lack of awareness among health professionals about the safety of herbal medicines. Thus, this study assessed the current awareness of health professionals on the safety of herbal medicine in the South West of Ethiopia.

Methodology: The study employed a cross-sectional study design involving multistage sampling among health professionals $(n=286)$ working in the medical center of Jimma University, January to February, 2021. The pre-tested self-administered questionnaire containing structured questions on a five-point Likert scale was appropriately filled and returned for statistical analysis. For the analysis of data, Statistical Package for Social Sciences (SPSS) was used. The associations between status of awareness and predictors were determined at $5 \%(p<0.05)$ level of significance by employing multivariate logistic regression.

Results: The study revealed around $51.8 \%$ of respondents had a good awareness regarding herbal medicine safety. Working experience of 6-10 years (AOR: 0.215, 95\% CI: 0.093, 0.499), having training (AOR: $0.357,95 \% \mathrm{CI}: 0.166,0.770$ ), and practice of safety monitoring (AOR: $0.169,95 \% \mathrm{CI}: 0.077,0.370$ ) were significantly associated with awareness of safety of herbal medicine.

Conclusion: This study revealed that awareness of health professionals regarding safety of herbal medicine is not satisfactory. The years of experience, training, and practice of safety monitoring of herbal medicine are the major factors affecting status awareness. Therefore, the National Regulatory Authority must urgently facilitate integrated and consistent training for all health professionals.

Keywords: awareness, healthcare professionals, herbal medicine, safety

\section{Introduction}

Herbal medicines are considered as a category of herbal products used for therapeutic purposes that are derived from plants and plant materials. ${ }^{1}$ They constitute different mixtures of organic chemicals that are obtained either from raw or processed sections of plants encompassing leaves, flowers, stems, seeds and roots. $^{2}$ In recent years, tremendous attention has given to herbal medicine use for treatment of many different diseases. ${ }^{3} \mathrm{Up}$ to four billion people in the developing world, which represents $80 \%$ of population of the world, rely on herbal medicine for primary health care. ${ }^{4}$ The demand has been increasing with the growing number
Correspondence: Gemmechu Hasen Jimma University, P.O.Box: 378, Jimma, Oromia, Ethiopia

Email gemmechuhasen2009@gmail.com 
of people, the shortage of modern medicines and unaffordable prices, the shortage of economy for controlling of non-communicable diseases as well as the growing social attitudes of several patients in developing countries. ${ }^{5,6}$ However, there is an increasing concern regarding herbal medicine safety, due to high demand of herbal medicine for management of several diseases. ${ }^{7-9}$ The recent reports revealed the suspected toxicity and unwanted reaction associated with safety of herbal medicine encompassing side effects due to reaction occurring as a result of overdoses, overdurations, tolerances, and hypersensitivity reaction, midterm and extended effects on different organs encompassing renal, liver, cardiac and neurotoxicity as well as teratogenic and genotoxicity. ${ }^{10}$ Moreover, secondary to the frequent reports of the aforementioned toxicities, the national regulatory agencies including the WHO (World Health Organization) have highly increased the concern of herbal medicine safety. ${ }^{11,12}$ Accordingly, the WHO has developed guidelines for monitoring of herbal medicine safety within the existing pharmacovigilance framework by recognizing the growing importance of herbal medicine utilization worldwide. ${ }^{13}$ Besides, the WHO has recommended active involvement of health professionals in monitoring of safety of the herbal medicine for adequate, effective monitoring of herbal medicine as special requirements. Moreover, a very recent study has indicated the importance of establishing effective herbal medicine policies and health education programs for enhancing patient-desired therapeutic outcome by identifying the benefits and risk of using herbal medicine. ${ }^{14}$

Thus, adequate awareness of health professionals regarding safety of herbal medicine is very crucial. Moreover, adequate provision of information for health professionals has been indicated to facilitate better understanding of the risk associated with utilization of herbal medicine, and to ensure that herbal medicines are safe and of suitable quality. ${ }^{15,16}$ Until recently, however, safety of herbal medicine particularly the interactions of herbal with modern drugs were not suspected among healthcare providers, including the trained physicians, and patients may also not always inform their doctors about the use of herbal medicines at the same time. ${ }^{17,18}$ Moreover, it has been reported that the healthcare provider professionals were unable to advise the patients on the safe use of herbal medicine due to lack of knowledge and insufficient training on herbal medicines. ${ }^{19}$ This situation is very severe in developing countries, particularly Ethiopia, where herbal medicines are poorly regulated, and herbal products are sold freely on the market with little or no restraint. Moreover, studies that describe awareness of health professionals regarding safety of herbal medicine is lacking. Hence, the purpose of this study was to assess current awareness of healthcare professionals on safety of herbal medicine in the South West of Ethiopia.

\section{Methodology}

\section{Study Design and Location}

The study employed a cross-sectional study design involving multistage sampling among health professionals $(n=286)$ working in the medical center of Jimma University, January to February, 2021. Geographically, the medical center of Jimma University is located in Jimma Town, and $350 \mathrm{~km}$ from Addis Ababa, the capital of Ethiopia. The center provides the major services encompassing 9 medicals and other clinical and diagnostic departments. Approximately, 15,000 inpatients and 160 outpatients, 11, 000 emergency cases, and 450 deliveries came to the center in year from a catchment population of about 15 million.

\section{Sample Population, Size, and Sampling Technique}

The Raosoft sample size calculator was employed to determine the sample size. ${ }^{20}$ Two hundred and seventy-three sample sizes of populations were obtained by considering $5 \%$ margin of error, $95 \%$ confidence interval, and $50 \%$ distribution of the response for an approximate population of 950, a total of health professionals working in Jimma University Medical Center (JUMC). Allowing for 5\% dropout, 286 participants were included in the study. For selecting study participants, Jimma University health professionals were stratified into departments and/or clusters (Medical doctors, Nurses, and Pharmacy). Then, a convenience sampling method was used to select study participants $(n=286)$ through proportional allocation to each cluster of the department.

\section{Data Collection Procedure}

To collect data from study participants the pre-tested selfadministered questionnaire was employed. The questionnaire was designed and validated based on extensive review of previous literatures in English language. ${ }^{21-25}$ Three experts have examined the face validity as well as 
readability of the questionnaire in two rounds of review, placing attention on easy comprehension of the questionnaire to gear to general populations. Then, the pre-test was carried out on around 10 non-health professionals. Accordingly, based on feedback, modification was made as necessary to the final version of the questionnaire. For the purpose of consistency an English version of the questionnaire was translated to Afaan Oromo and Amharic, local languages, and reversed to English. The questionnaire encompasses three sections; the first part was used to assess the sociodemographic characteristics, and the second part assessed the practice and monitoring of the herbal medicine. The last section of the questionnaire was used for evaluation of the level of awareness of the health professionals on safety of the herbal medicine. Thus, the Likert items were calculated on a 1-5 response scale, where strongly agree (5), agree (4), neutral (3), disagree (2), and strongly disagree (1), with the objective of determining the level of health professional awareness on safety of the herbal medicine. To ensure this objective, awareness levels of the respondents were assessed; their responses were dichotomized into good awareness and low awareness after computing the overall mean, from each calculated mean score of awareness for all health professionals. Accordingly, good awareness earns a mean score greater than or equal to the overall mean, while low awareness possesses a mean score less than the overall mean.

\section{Statistical Analysis}

All the filled questionnaires were checked to ensure their completeness before they were manually entered into Statistical Package for Social Sciences (SPSS) Version 21.0 (IBM Corporation, Armonk, NY, USA) based on appropriate coding and scoring formats for analysis. The results were summarized using descriptive statistics. The associations between status of awareness and predictors were determined at $5 \%(p<0.05)$ level of significance by employing multivariate logistic regression after analysis of the bivariate logistic regression that was used to check the significance of association between the outcome and independent variables.

\section{Results}

\section{Characteristics of Study Participants}

Out of 286 participants invited, 270 responded to the study yielding a $94.4 \%$ response rate. Among the study participants, the majority of respondents $140(51.9 \%)$ were medical doctors and 88 (32.6\%) were nurses, while $42(15.6 \%)$ constituted pharmacy professionals. The results also revealed the respondent's age resides within 25-30 years. Concerning years of experience, the majority of study participants $137(50.7 \%)$ had experience of 1-5 years (Table 1).

\section{Use, Practice, and Monitoring Safety of Herbal Medicine}

Of study respondents, the majority 163 (60.4\%) study participants used herbal medicine. Around 76 (28.1\%) of study participants had a training regarding safety of herbal medicine. Moreover, 112 (41.5\%) of respondents faced patients who have experienced side effects as the used of drug and herb concomitantly (Table 2).

\section{Awareness of Health Professionals on the Safety of Herbal Medicines}

Awareness of health professional measurements based on seven (7) items on a five-point Likert scale showed the overall mean was $3.64 \pm 0.44$ (Figure 1). Besides, the dichotomized level of awareness based on the overall mean revealed about $51.8 \%$ of the respondents had

Table I Respondents' Sociodemographic Characteristics

\begin{tabular}{|c|c|c|c|}
\hline \multicolumn{2}{|c|}{ Study Variables } & \multirow{2}{*}{$\begin{array}{l}\text { Frequency } \\
(n=270)\end{array}$} & \multirow{3}{*}{$\begin{array}{l}\begin{array}{l}\text { Percentage } \\
(\%)\end{array} \\
51.1 \\
48.9\end{array}$} \\
\hline Gender & Male & & \\
\hline & Female & 132 & \\
\hline \multirow[t]{4}{*}{ Age } & $25-30$ years & 137 & 50.7 \\
\hline & $30-35$ years & 74 & 27.4 \\
\hline & $35-40$ years & 22 & 8.1 \\
\hline & $>40$ years & 37 & 13.7 \\
\hline \multirow[t]{4}{*}{ Marital status } & Married & 78 & 28.9 \\
\hline & Divorced & 17 & 6.3 \\
\hline & Single & 160 & 59.3 \\
\hline & Others & 15 & 5.6 \\
\hline \multirow{3}{*}{$\begin{array}{l}\text { Professional } \\
\text { category }\end{array}$} & Medical doctor & 140 & 51.9 \\
\hline & Pharmacist & 42 & 15.6 \\
\hline & Nurse & 88 & 32.6 \\
\hline \multirow{3}{*}{$\begin{array}{l}\text { Years of } \\
\text { experience }\end{array}$} & $\mathrm{I}-5$ years & 177 & 65.6 \\
\hline & $6-10$ years & 85 & 31.5 \\
\hline & $>10$ years & 8 & 3.0 \\
\hline \multirow{4}{*}{$\begin{array}{l}\text { Department } \\
\text { they work in }\end{array}$} & Emergency room & 33 & 12.2 \\
\hline & Outpatient department & 70 & 25.9 \\
\hline & Ward & 147 & 54.4 \\
\hline & Others & 20 & 7.4 \\
\hline
\end{tabular}


Table 2 Utilization, Practice, and Monitoring of the Herbal Medicine of the Respondents

\begin{tabular}{|c|c|c|c|}
\hline \multicolumn{2}{|l|}{ Items } & \multirow{3}{*}{$\begin{array}{l}\text { Frequency } \\
(\mathbf{n}=\mathbf{2 7 0})\end{array}$} & \multirow{3}{*}{$\begin{array}{l}\text { Percentage } \\
(\%) \\
60.4 \\
39.6\end{array}$} \\
\hline Have you ever used herbal medicine? & Yes & & \\
\hline & No & & \\
\hline \multirow[t]{2}{*}{ Do you have a training regarding safety of herbal medicine? } & Yes & 76 & 28.1 \\
\hline & No & 194 & 71.9 \\
\hline \multirow[t]{2}{*}{ Have you experienced side effects after consuming herbal medicine } & Yes & 46 & 17.0 \\
\hline & No & 224 & 83.0 \\
\hline \multirow[t]{2}{*}{ Do you monitor safety of herbal medicines? } & Yes & 75 & 27.8 \\
\hline & No & 195 & 72.2 \\
\hline \multirow[t]{2}{*}{ Do you have any information about drug herb interaction? } & Yes & 194 & 71.9 \\
\hline & No & 76 & 28.1 \\
\hline \multirow{2}{*}{$\begin{array}{l}\text { Have you faced a patient who experienced side effects during the concomitant use of drug } \\
\text { and herb? }\end{array}$} & Yes & 112 & 41.5 \\
\hline & No & 158 & 58.5 \\
\hline
\end{tabular}

a good awareness of herbal medicine safety (Figure 2). medicine to the national pharmacovigilance centre The majority of respondents agreed to each item, except (Table 3). The detailed evaluation of the level of awareitem number 6 , in which no respondents have experience ness among health professionals on herbal medicine safety of reporting the suspected adverse reactions of herbal using Likert-scale questions is portrayed in Table 3.

\section{Distribution of calculated mean}

Mean $=3.64$

Ste.Dev. $=0.44$

$\mathrm{N}=270$

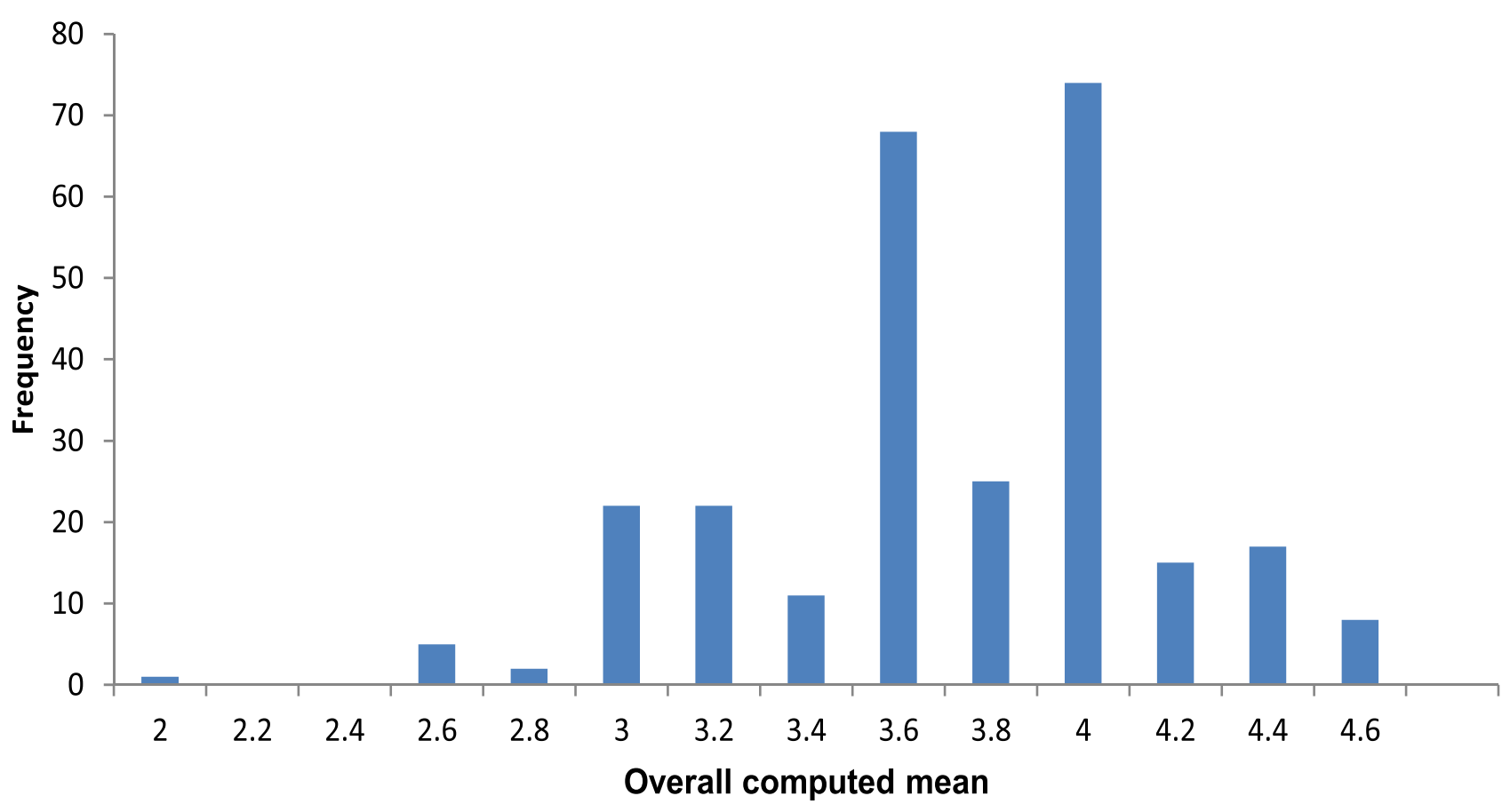

Figure I Computed overall mean of study participants based on seven-item Likert scale. 


\section{Status of awareness}

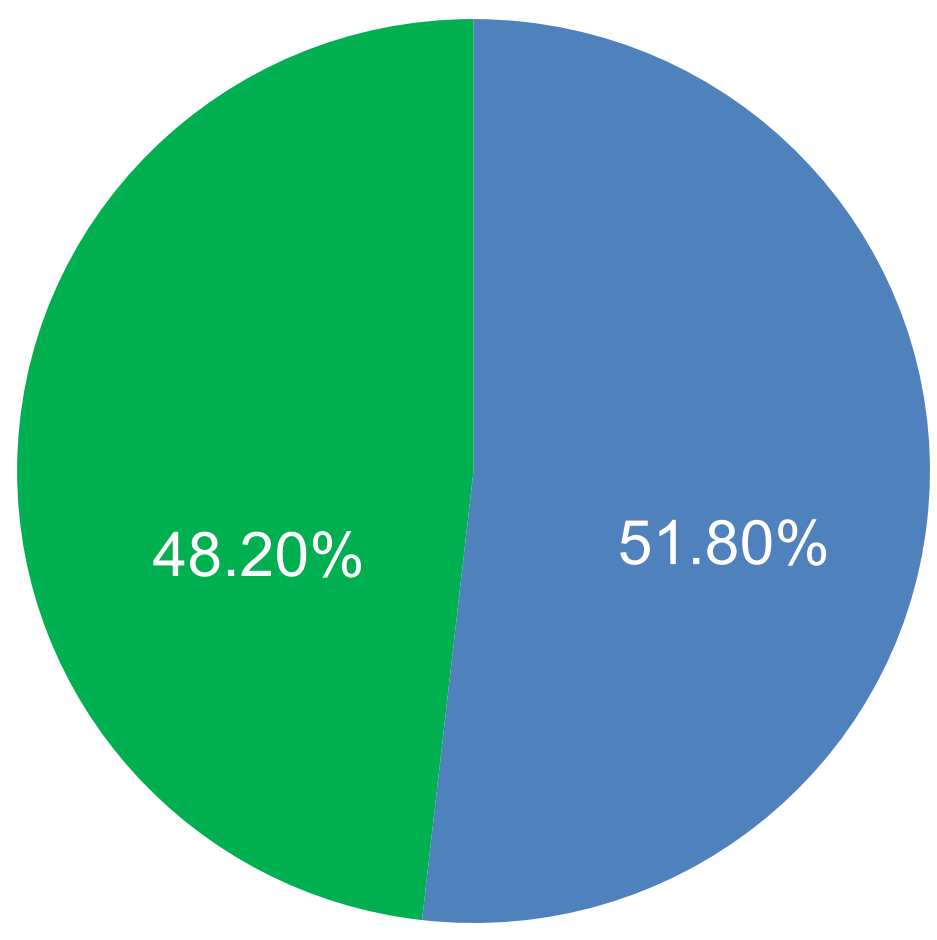

\section{- Good awareness - Low awareness}

Figure 2 Status of awareness among study participants.

\section{Factors Associated with Herbal Medicine Safety Awareness}

Multivariate logistic regression revealed that age, years of experience, training regarding safety of herbal medicine, history of monitoring of the safety of herbal medicine, and met a patient who experienced side effect after having herbal medicine were significantly associated with awareness of herbal medicine safety (Table 4 ). Health professionals whose age ranged between $31-35$ years were 2.54 times higher to have awareness of the safety of herbal medicine as compared to those whose age was between 25-30 years (AOR: 2.54, 95\% CI: 1.082, 5.962) while those whose age ranged between 36-40 years were 4.023 times higher (AOR: 4.023, 95\% CI: 1.062, 15.248). Respondents who had experience of 1-5 years were 78.5 times less likely have an awareness of safety of herbal medicines as those who had 6-10 years of experience (AOR: 0.215, 95\% CI: 0.093, 0.499). Study participants who had no training on the safety of herbal medicine were 64.3 times less likely to have an awareness of safety of herbal medicines as those who had training (AOR: 0.357, 95\% CI: 0.166, 0.770). Moreover, health professional whose who did not monitor of the safety of herbal medicine were 83.1 times less likely have an awareness of safety of herbal medicines as those who did monitor herbal medicine safety (AOR: 0.169, 95\% CI: 0.077, $0.370)$.

\section{Discussion}

The importance of herbal medicine safety monitoring has been highlighted in many recent findings, ${ }^{7-12}$ and has become a burning concern for both general public and national regulatory authorities. As a result, the World Health Organization has strongly warned of the safety monitoring of herbal medicine within the existing pharmacovigilance system, and highly recommended the involvements of health professionals for appropriate monitoring of the safety of herbal medicine. ${ }^{13}$

However, it has been repeatedly indicated that health professionals working in the world, particularly in developing countries, have limited awareness regarding monitoring of the safety of herbal medicine. ${ }^{15-18}$ Thus, assessing the awareness of health professionals regarding safety of herbal medicine is very crucial, which will facilitate the development of a national pharmacovigilance system for herbal medicines. Moreover, it will highlight the urgency of providing training regarding safety of herbal medicine for health professionals especially; a low income country like Ethiopia thus helps creation of 
Table 3 Evaluation of Level of Awareness on Herbal Medicines Safety Among Health Professionals Using Likert-Scale Questions

\begin{tabular}{|c|c|c|c|c|c|}
\hline $\begin{array}{l}\text { Items for Assessment of the Level of Awareness Regarding Safety of } \\
\text { Herbal Medicine }\end{array}$ & $\begin{array}{l}\text { Strongly } \\
\text { Agree } \\
\text { (\%) }\end{array}$ & $\begin{array}{l}\text { Agree } \\
(\%)\end{array}$ & $\begin{array}{l}\text { Neutral } \\
(\%)\end{array}$ & $\begin{array}{l}\text { Disagree } \\
(\%)\end{array}$ & $\begin{array}{l}\text { Strongly } \\
\text { Disagree } \\
\text { (\%) }\end{array}$ \\
\hline $\begin{array}{l}\text { Concomitant use of herbal medicines with conventional drugs may causes } \\
\text { potential pharmacokinetic interactions }\end{array}$ & 24.1 & 36.7 & 34.1 & 3.7 & 1.5 \\
\hline $\begin{array}{l}\text { Herbal medicine products could inhibit and/or induce drug-metabolizing } \\
\text { enzymes }\end{array}$ & 26.7 & 43.7 & 27.4 & 2.2 & 0 \\
\hline $\begin{array}{l}\text { Currently, there is misunderstanding and prejudice toward herbal medicine } \\
\text { safety }\end{array}$ & 18.1 & 48.5 & 31.9 & 1.5 & 0 \\
\hline $\begin{array}{l}\text { The factors that affect quality of herbal medicine could compromise the safety } \\
\text { of herbal medicine }\end{array}$ & 10.7 & 58.1 & 28.9 & 2.2 & 0 \\
\hline $\begin{array}{l}\text { It is a role of health professionals including physicians, pharmacists, and nurses } \\
\text { who should report suspected adverse reactions of herbal medicine to the } \\
\text { national pharmacovigilance centre }\end{array}$ & 25.6 & 61.1 & II.I & 1.5 & 0.7 \\
\hline $\begin{array}{l}\text { I have experience of reporting the suspected adverse reactions of the herbal } \\
\text { medicine to the national health pharmacovigilance centre }\end{array}$ & 0 & 0 & 52.6 & 25.6 & 21.9 \\
\hline $\begin{array}{l}\text { The treatment outcome may be affected when patients take herbal medicine } \\
\text { before coming to health facilities }\end{array}$ & 10.4 & 56.7 & 31.1 & 1.5 & 0.4 \\
\hline
\end{tabular}

adequate awareness on safety of herbal medicine among health professionals.

In this study, about $51.8 \%$ of respondents had a good awareness regarding safety of herbal medicine. Compared with study findings in Malaysia, ${ }^{22}$ which had reported a higher percentage of level awareness, the present study revealed lower level of awareness of herbal medicine safety. This difference may be related to employment of different study approaches, as the current study evaluated the level of awareness based on structured questions on a five-point Likert scale, which is very important to reduce bias as it allow respondents to express both the direction and strength of their opinion about a topic. ${ }^{26}$

The majority of study participants agreed that health professionals have a crucial responsibility in monitoring of herbal medicine safety. This finding strongly strengthens the recommendations already highlighted by the WHO that has indicated the importance of involving health professionals in monitoring of the safety of herbal medicine. ${ }^{13}$ The current study is also in line with recent reports that have evidenced the importance of enhancing the awareness of health professionals about the use herbal medicines for making better informed decisions, ${ }^{19}$ and establish the effective herbal medicine policies and health education programs. ${ }^{14}$ Contrarily, more than half of the respondents did not agree, as concomitant use of herbal medicine with conventional drugs could cause potential pharmacokinetic interactions. This is consistent with previously reported findings, in which health professionals lacked awareness regarding potential interactions between herbal products and modern drugs. ${ }^{27,28}$

Moreover, the multivariate logistic regression revealed that age, years of experience, training regarding safety of herbal medicine, and history of monitoring of the safety of herbal medicine were significantly associated with awareness of safety of herbal medicine. These significances have revealed the predictors for awareness of health professionals regarding herbal medicine safety.

\section{Conclusions}

The present study revealed that awareness levels of healthcare professionals on the safety of herbal medicine in the study area is not satisfactory; with age, years of experience, and training as major factors affecting the awareness levels of the respondents. Therefore, the National Regulatory Authority must urgently facilitate integrated and consistent training for all healthcare professionals for the development of an effective pharmacovigilance framework to assist monitoring of herbal medicine safety. Furthermore, the findings implicate the need of 
Table 4 Predictors of Awareness Regarding Safety of Herbal Medicine

\begin{tabular}{|c|c|c|c|c|}
\hline \multirow[t]{2}{*}{ Study Variables } & \multicolumn{2}{|c|}{$\begin{array}{l}\text { Awareness of Herbal } \\
\text { Medicine Safety (\%) }\end{array}$} & \multirow[t]{2}{*}{ OR $(95 \% \mathrm{Cl})$} & \multirow[t]{2}{*}{$p$-Value } \\
\hline & $\begin{array}{l}\text { Good } \\
\text { Awareness }\end{array}$ & $\begin{array}{l}\text { Low } \\
\text { Awareness }\end{array}$ & & \\
\hline \multicolumn{5}{|l|}{ Age } \\
\hline $25-30$ years & $61(44.5 \%$ & $76(55.5 \%)$ & I & \\
\hline $31-35$ years & $49(66.2 \%)$ & 25 (33.8\%) & $2.540(1.082,5.962)^{*}$ & 0.013 \\
\hline $36-40$ years & $15(68.2 \%)$ & 7 (3I.8\%) & $4.023(1.062,15.248)^{*}$ & \\
\hline$>41$ years & $14(37.8 \%)$ & $23(62.2 \%)$ & $0.529(0.190,1.476)$ & \\
\hline \multicolumn{5}{|c|}{ Years of Experience } \\
\hline $\mathrm{I}-5$ years & $92(52.0 \%)$ & 85 (48.0\%) & I & \\
\hline $6-10$ years & $40(47.1 \%)$ & $45(52.9 \%)$ & $0.215(0.093,0.499)^{*}$ & 0.000 \\
\hline$\geq 1 \mathrm{I}$ years & 7 (87.5\%) & I (I2.5\%) & $9.430(0.520,171.022)$ & \\
\hline \multicolumn{5}{|c|}{ Training Regarding Safety of Herbal Medicine } \\
\hline Yes & 57 (75.0\%) & $19(25.0 \%)$ & I & \\
\hline No & $82(42.3 \%)$ & $112(57.7 \%)$ & $0.357(0.166,0.770)^{*}$ & 0.009 \\
\hline \multicolumn{5}{|c|}{ Side effects Manifested Due to Herbal Medicine Use } \\
\hline Yes & $35(76.1 \%)$ & II (23.9\%) & I & \\
\hline No & $104(46.4 \%)$ & $120(53.6 \%)$ & $0.335(0.123,9.11)$ & 0.032 \\
\hline \multicolumn{5}{|c|}{ Monitor Safety of Herbal Medicine } \\
\hline Yes & $63(84.0 \%)$ & $12(16.0 \%)$ & I & \\
\hline No & $76(39.0 \%)$ & $119(61.0 \%)$ & $0.169(0.077,0.370)^{*}$ & 0.000 \\
\hline \multirow{2}{*}{\multicolumn{5}{|c|}{$\begin{array}{l}\text { Faced Patient Who Experienced Side Effect After Having } \\
\text { Herbal Medicines }\end{array}$}} \\
\hline & & & & \\
\hline Yes & $83(74.1 \%)$ & $29(25.9 \%)$ & I & \\
\hline No & $56(35.4 \%)$ & $102(64.6 \%)$ & $0.378(0.186,1.766)$ & 0.007 \\
\hline
\end{tabular}

Note: $*$ Statistically significant at $95 \% \mathrm{Cl}$.

Abbreviations: $\mathrm{Cl}$, confidence interval; OR, odds ratio.

comprehensive study on how health professionals manage prehospital use of herbal medicine.

\section{Data Sharing Statement}

The documents supporting this study will be available upon request from corresponding author.

\section{Ethical Approval and Consent to Participate}

Ethical principles mentioned in the Helsinki Declaration were followed for undertaking this study. It was approved by the institutional review board of Jimma University. A letter of permission was received from the office of Chief Executive Officer of Jimma University Medical Center. The informed consent of the study participants was taken prior to interviews for collection of data. The withdrawal right of study participants from involvements of study at any time was assured.

\section{Acknowledgments}

The authors would like to extend heartfelt gratitude to all study respondents for accepting the invitation to be involved in this study.

\section{Author Contributions}

Both authors made a significant contribution to the work reported, whether that is in the conception, study design, execution, acquisition of data, analysis, and interpretation, or in all these areas; took part in drafting, revising, or critically reviewing the article; gave final approval of the version to be published; have agreed on the journal to which the article has been submitted; and agree to be accountable for all aspects of the work.

\section{Disclosure}

The authors report no conflicts of interest in this work. 


\section{References}

1. Calapai G. European legislation on herbal medicines: a look into the future. Drug Saf. 2008;31(5):428-431. doi:10.2165/00002018200831050-00009

2. Bent S. Herbal medicine in the United States: review of efficacy, safety, and regulation - Grand Rounds at University of California, San Francisco Medical Center. J Gen Intern Med. 2008;23 (6):854-859. doi:10.1007/s11606-008-0632-y

3. Aziato L, Odai PNA. Exploring the safety and clinical use of herbal medicine in the contemporary Ghanaian context: a descriptive qualitative study. J Herb Med. 2017;8(62-7). doi:10.1016/j. hermed.2016.11.002.

4. Zhang J, Onakpoya IJ, Posadzki P, Eddouks M. The safety of herbal medicine: from prejudice to evidence. Evidence-Based Complement Altern Med. 2015. doi:10.1155/2015/316706

5. Mesfin F, Seta T, Assefa A. An ethnobotanical study of medicinal plants in Amaro Woreda, Ethiopia. Ethnobot Res Appl. 2014;12:341-354. doi:10.17348/era.12.0.341-354

6. Hughes GD, Aboyade OM, Beauclair R, Mbamalu ON, Puoane TR. Characterizing herbal medicine use for noncommunicable diseases in urban South Africa. Evidence-Based Complement Altern Med. 2015.

7. Saad B, Azaizeh H, Abu-Hijleh G, Said O. Safety of traditional Arab herbal medicine. Evidence-Based Complement Altern Med. 2006;3 (4):433-439. doi:10.1093/ecam/nel058

8. Jeong TY, Park BK, Cho JH, Kim Y Il, Ahn YC, Son CG. A prospective study on the safety of herbal medicines, used alone or with conventional medicines. J Ethnopharmacol. 2012;143 (3):884-888. doi:10.1016/j.jep.2012.08.016

9. Rodriguez-Fragoso L, Reyes-Esparza J, Burchiel SW, Herrera-Ruiz D, Torres E. Risks and benefits of commonly used herbal medicines in Mexico. Toxicol Appl Pharmacol. 2008;227(1):125-135. doi:10.1016/j.taap.2007.10.005

10. Shaw D, Graeme L, Pierre D, Elizabeth W, Kelvin C. Pharmacovigilance of herbal medicine. $J$ Ethnopharmacol. 2012;140(3):513-518. doi:10.1016/j.jep.2012.01.051

11. Nortier JL, Vanherweghem JL. For patients taking herbal therapy Lessons from aristolochic acid nephropathy. Nephrol Dial Transplant. 2007;22(6):1512-1517. doi:10.1093/ndt/gfm167

12. Hong M, Li S, Tan HY, Wang N, Tsao SW, Feng Y. Current status of herbal medicines in chronic liver disease therapy: the biological effects, molecular targets and future prospects. Int $J$ Mol Sci. 2015;16(12):28705-28745. doi:10.3390/ijms161226126

13. World Health Organization (WHO). WHO guidelines on safety monitoring of herbal medicines in pharmacovigilance systems. World Heal Organ Geneva. [Internet]; 2004: 82. Available from: https://apps.who.int/medici nedocs/documents/s7148e/s7148e.pdf. Accessed July 15, 2021.

14. El-Dahiyat F, Rashrash M, Abuhamdah S, Abu Farha R, Babar ZUD. Herbal medicines: a cross-sectional study to evaluate the prevalence and predictors of use among Jordanian adults. $J$ Pharm Policy Pract. 2020;13(1):1-9. doi:10.1186/s40545-019-0200-3
15. Ekor M. The growing use of herbal medicines: issues relating to adverse reactions and challenges in monitoring safety. Front Neurol. 2014;4:1-10.

16. Mohammad-Reza Ardalan MR-K.Is the safety of herbal medicines for kidneys under question? J Nephropharmacol. 2013;2(2):11-12.

17. Fasinu PS, Bouic PJ, Rosenkranz B. An overview of the evidence and mechanisms of herb-drug interactions. Front Pharmacol. 2012;3:1-19. doi:10.3389/fphar.2012.00069

18. Werneke U, Earl J, Seydel C, Horn O, Crichton P, Fannon D. Potential health risks of complementary alternative medicines in cancer patients. Br J Cancer. 2004;90(2):408-413. doi:10.1038/sj. bjc. 6601560

19. Bhamra SK, Slater A, Howard C, Heinrich M, Johnson MRD. Health care professionals' personal and professional views of herbal medicines in the United Kingdom. Phyther Res. 2019;33(9):2360-2368. doi: $10.1002 /$ ptr.6418

20. Raosoft ${ }^{\circledR}$ sample size calculator. Available from: https://www.raosoft. com/samplesize.html. Accessed December 23, 2020.

21. Laelago T, Yohannes T, Lemango F. Prevalence of herbal medicine use and associated factors among pregnant women attending antenatal care at public health facilities in Hossana Town, Southern Ethiopia: facility based cross sectional study. Arch Public Heal. 2016;74(1):1-8. doi:10.1186/s13690-016-0118-z

22. Silvanathan S, Low BS. Current public awareness on the safety of traditional and complementary medicines (T\&CM) in Malaysia. Eur J Integr Med. 2015;7(2):184-189. doi:10.1016/j.eujim.2014.12.003

23. Khan A, Ahmed ME, Aldarmahi A, et al. Awareness, self-use, perceptions, beliefs, and attitudes toward complementary and alternative medicines (CAM) among health professional students in King Saud bin Abdulaziz University for Health Sciences Jeddah, Saudi Arabia. Evidence-Based Complement Altern Med. 2020.

24. Awad A, Al-Shaye D. Public awareness, patterns of use and attitudes toward natural health products in Kuwait: a cross-sectional survey. BMC Complement Altern Med. 2014;14:1-11. doi:10.1186/14726882-14-105

25. Bai Y, Li J, Bai Y, Ma W, Yang X, Ma F. Development and validation of a questionnaire to evaluate the factors influencing training transfer among nursing professionals. BMC Health Serv Res. 2018;18(1):1-9.

26. Chyung SYY, Roberts K, Swanson I, Hankinson A. Evidence-based survey design: the use of a midpoint on the likert scale. Perform Improv. 2017;56(10):15-23. doi:10.1002/pfi.21727

27. Woodward KN. The potential impact of the use of homeopathic and herbal remedies on monitoring the safety of prescription products. Hum Exp Toxicol. 2005;24(5):219-233. doi:10.1191/096032710 $5 \mathrm{ht} 529 \mathrm{oa}$

28. Abahussain NA, Abahussain EA, Al-Oumi FM. Pharmacists' attitudes and awareness towards the use and safety of herbs in Kuwait. Pharm Pract (Granada). 2007;5(3):125-129. doi:10.4321/S188636552007000300005
Journal of Multidisciplinary Healthcare

\section{Publish your work in this journal}

The Journal of Multidisciplinary Healthcare is an international, peerreviewed open-access journal that aims to represent and publish research in healthcare areas delivered by practitioners of different disciplines. This includes studies and reviews conducted by multidisciplinary teams as well as research which evaluates the results or conduct of such teams or healthcare processes in general. The journal covers a very wide range of areas and welcomes submissions from practitioners at all levels, from all over the world. The manuscript management system is completely online and includes a very quick and fair peer-review system. Visit http://www.dovepress.com/testimonials. php to read real quotes from published authors. 